\title{
Doença cerebrovascular na infância e adolescência: estudo das habilidades de processamento auditivo (central)
}

\author{
Karla Maria Ibraim da Freiria Elias ${ }^{1}$
}

Elias KMIF. Doença cerebrovascular na infância e adolescência: estudo das habilidades de processamento auditivo (central) [tese de doutorado]. Campinas: Faculdade de Ciências Médicas da Universidade Estadual de Campinas; 2008.

$\mathrm{Na}$ infância e adolescência, a doença cerebrovascular (DCV) constitui condição rara, de etiologia variada, em que a evolução a curto e longo prazo tem merecido esclarecimentos. Em anos recentes, a clássica impressão de recuperação favorável após eventos vasculares nesta população tem sido esmaecida com a verificação de variáveis índices de alterações comportamentais, cognitivas, linguísticas e de aprendizagem. No referente ao processamento das informações auditivas o conhecimento é ainda bastante restrito e, diante desta constatação, nos propusemos a realizar ampla investigação desta função, através da aplicação de testes de categorias diversas e estabelecer o grau de competência auditiva na dependência das características lesionais. Assim, o principal objetivo desde estudo, foi avaliar as habilidades de processamento auditivo (central) em crianças e adolescentes acometidos pela DCV, grupo propósito (GP), comparando-os, com grupo controle (GC), composto por crianças destras, de mesmo gênero, idade e nível socioeconômico das crianças do GP. Na avaliação audiológica foram aplicados os seguintes testes: localização sonora em cinco direções, memória sequencial verbal e nãoverbal, na categoria de avaliação simplificada; teste de fala com ruído e de fala filtrada, na categoria dos monóticos de baixa redundância; dicótico não-verbal, consoante-vogal, dicótico de dígitos e dicótico de dissílabos alternados (Staggered Spondaic Word test - SSW) na dos dicóticos; padrão de frequência e de duração, na de testes de processamento temporal. Os dados foram analisados através de metodologia estatística pertinente - teste exato de Fisher e Wilcoxon - e revelaram desempenho similar entre os grupos nos testes de localização sonora e fala com ruído. Nos demais testes, o GP apresentou desempenho significativamente inferior ao GC, revelando alterações nas habilidades auditivas de fechamento, memória, atenção seletiva e processamento temporal. Os testes de fala filtrada e de padrão de duração foram, respectivamente, mais sensíveis que os testes de fala com ruído e padrão de frequência, na identificação de alterações nas habilidades de fechamento auditivo e de ordenação temporal. Adicionalmente, a presença da lesão e não suas características foram determinantes para a definição do grau da competência auditiva. Através do presente estudo, pudemos ampliar o conhecimento evolutivo da DCV infantil ao demonstrar comprometimento de habilidades específicas de processamento auditivo.

Trabalho apresentado à Faculdade de Ciências Médicas da Universidade Estadual de Campinas - UNICAMP - Campinas (SP), Brasil, para obtenção do título de Doutor em Ciências Médicas, área de Ciências Biomédicas, sob orientação da Profa Dra Maria Valeriana Leme de Moura-Ribeiro.

(1) Doutora, Fonoaudióloga da Associação Paparella de Otorrinolaringologia -APO - Ribeirão Preto (SP), Brasil.

Endereço para correspondência: Karla Maria Ibraim da Freiria Elias. Associação Paparella de Otorrinolaringologia - Centro Clínico Electro Bonini. Av. Leão XIII, s/n, sala 15, Ribeirão Preto - SP, CEP 14096-380. E-mail: karla@fcm.unicamp.br 